\title{
Leptin and leptin receptor expression in asthma
}

\author{
Andreina Bruno, PhD, ${ }^{a}$ Elisabetta Pace, MD, ${ }^{a}$ Pascal Chanez, MD, ${ }^{b}$ Delphine Gras, PhD, ${ }^{b}$ Isabelle Vachier, PhD, ${ }^{\mathrm{c}}$ \\ Giuseppina Chiappara, PhD, ${ }^{a}$ Maurizio La Guardia, MD, ${ }^{d}$ Stefania Gerbino, PhD, ${ }^{\text {a,d }}$ Mirella Profita, PhD, ${ }^{a}$ \\ and Mark Gjomarkaj, MD ${ }^{\mathbf{a}}$ Palermo, Italy, and Marseille and Montpellier, France
}

Background: The adipokine leptin is a potential new mediator for bronchial epithelial homeostasis. Asthma is a chronic inflammatory disease characterized by airway remodeling that might affect disease chronicity and severity. TGF- $\beta$ is a tissue growth factor the dysregulation of which is associated with airway remodeling.

Objective: We sought to determine whether a bronchial epithelial dysfunction of the leptin/leptin receptor pathway contributes to asthma pathogenesis and severity.

Methods: We investigated in vitro the presence of leptin/leptin receptor on human bronchial epithelial cells. Then we studied the effect of TGF- $\beta$ and fluticasone propionate on leptin receptor expression. Finally, the role of leptin on TGF- $\beta$ release and cell proliferation was analyzed. $E x$ vivo we investigated the presence of leptin/leptin receptor in the epithelium of bronchial biopsy specimens from subjects with asthma of various severities and from healthy volunteers, and some features of airway remodeling, such as reticular basement membrane (RBM) thickness and TGF- $\beta$ expression in the epithelium, were assessed.

Results: In vitro bronchial epithelial cells express leptin/leptin receptor. TGF- $\beta$ decreased and fluticasone propionate increased leptin receptor expression, and leptin decreased the spontaneous release of TGF- $\beta$ and increased cell proliferation. $E x$ vivo the bronchial epithelium of subjects with mild, uncontrolled, untreated asthma showed a decrease expression of leptin and its receptor and an increased RBM thickness and TGF- $\beta$ expression when compared with values seen in healthy volunteers. Furthermore, severe asthma was associated with a reduced expression of leptin and its receptor and an increased RBM thickness with unaltered TGF- $\beta$ expression.

Conclusions: Decreased expression of leptin/leptin receptor characterizes severe asthma and is associated with airway remodeling features. (J Allergy Clin Immunol 2009;124:230-7.)

\footnotetext{
From a Istituto di Biomedicina e Immunologia Molecolare (IBIM), Consiglio Nazionale delle Ricerche (CNR), Palermo; 'bépartement des Maladies Respiratoires, AP-HM Laboratoire d'immunologie INSERM CNRS U 600, UMR6212, Université de la Méditerranée, Marseille; ${ }^{\mathrm{C}} \mathrm{MED}$ BIO MED Service des maladies respiratoires CHU Montpellier; and ${ }^{\mathrm{d}}$ Sezione di Fisiologia e nutrizione umana, Dipartimento (DIMPEFINU), Università di Palermo.

Supported by INSERM-CNR contract.

Disclosure of potential conflict of interest: P. Chanez has received research support from Schering-Plough and has served as an advisor for all of the respiratory drug companies. The rest of the authors have declared that they have no conflict of interest.

Received for publication October 27, 2008; revised April 27, 2009; accepted for publication April 27, 2009.

Available online June 22, 2009.

Reprint requests: Andreina Bruno, PhD, Istituto di Biomedicina e Immunologia Molecolare (IBIM), Consiglio Nazionale delle Ricerche (CNR), Via Ugo La Malfa, 153, 90146 Palermo, Italy. E-mail: andreina@neomedia.it.

0091-6749/\$36.00

(C) 2009 American Academy of Allergy, Asthma \& Immunology

doi:10.1016/j.jaci.2009.04.032
}

Key words: Leptin, leptin receptor, severe asthma, epithelium, $T G F-\beta$, remodeling

Leptin, a 16-kd adipocyte-derived hormone originally described in metabolism regulation, plays a pleiotropic role in the immune system and inflammation. ${ }^{1}$ Leptin exerts its action through the leptin receptor (Ob-R) by activating both phosphatidylinositol-3-OH kinase and mitogen-activated protein kinase signaling pathways. ${ }^{2,3} \mathrm{Ob}-\mathrm{R}$ belongs to the glycoprotein 130 family of cytokine class I receptors and is present in many tissues, including the brain, placenta, hematopoietic cells, liver, heart, and lung. ${ }^{4}$ During skin repair, ${ }^{5}$ leptin might function as a regulatory link between the endocrine and immune systems and might represent a bridge between inflammation and tissue repair. It also contributes to regulation of the maturation of fetal lung cells ${ }^{6}$ and to homeostasis of the endothelium. ${ }^{7}$ Leptin is increased during allergic reactions in the airways and might play a role in the relationship between obesity and asthma. ${ }^{8}$ The specific role of the leptin/leptin receptor pathway in the bronchial epithelium from asthmatic patients is still largely unexplored. In patients with asthma, there is increasing evidence for an important role played by the epithelium in orchestrating the inflammatory responses and in producing a chronic wound scenario involving tissue injury and aberrant repair leading to airway remodeling. ${ }^{9}$ Airway remodeling has been related to the severity of asthma, and consistently, major tissue changes have been observed in patients with fatal asthma. ${ }^{10}$ Subepithelial thickening caused by excessive collagen deposition beneath the reticular basement membrane (RBM) is one of the most frequent features of airway remodeling in patients with asthma. ${ }^{11-14}$ TGF- $\beta$, a cytokine overexpressed in patients with asthma, is considered one of the major fibrogenic factors. It exists in 3 pleiotropic isoforms that play important roles in the regulation of inflammation, cell growth, differentiation, and wound healing. The expression of TGF- $\beta$ correlates with the degree of subepithelial changes in patients with asthma, ${ }^{15}$ and its production is downregulated by corticosteroids. ${ }^{16}$ Inhaled corticosteroids and bronchodilators are the mainstay of treatment in persistent asthma, but they are relatively less effective in the treatment of severe asthma. ${ }^{17,18}$ It has been assessed that synthetic dexamethasone stimulates both leptin synthesis in preadipocytes $^{19}$ and adipocytes ${ }^{20}$ and increases leptin secretion and leptin receptor mRNA expression in choriocarcinoma cells, ${ }^{21}$ whereas the addition of TGF- $\beta$ in the presence of dexamethasone blocks cell numbers in preadipocytes culture. ${ }^{19}$

The present study was performed to investigate both in vitro and ex vivo the role of the leptin/leptin receptor pathway and its relationship with different aspects of airway remodeling and regarding various aspects of human asthma, including the response to corticosteroids. 
Abbreviations used

BECs: Bronchial epithelial cells from brushings

FP: Fluticasone propionate

C: Healthy control volunteer

ICS: Subject with mild asthma controlled with inhaled corticosteroids

NHBE: Normal human bronchial epithelial

RBM: Reticular basement membrane

SDA: Subject with severe uncontrolled asthma treated with inhaled and oral corticosteroids

UA: Subject with mild uncontrolled untreated asthma

\section{METHODS}

This study was approved by the local ethics committee, and all patients provided written informed consent.

\section{Cell cultures}

The human bronchial epithelial SV40 immortalized cell line 16HBE $14 \mathrm{o-},{ }^{22}$ primary normal human bronchial epithelial (NHBE) cells (Lonza, Brussels, Belgium), and bronchial epithelial cells (BECs) from bronchial brushings were investigated. The detailed methods for cell-line cultures and immunocytochemistry are described in the Methods section of this article's Online Repository, which is available at www.jacionline.org.

\section{Confocal laser scanning microscopy}

Cytospin preparations were created from in vitro differentiated NHBE cells, and cells were fixed and permeabilized as previously described. ${ }^{2,3}$ Immunofluorescent staining was performed with the rabbit polyclonal antibody $\mathrm{Ob}$ anti-leptin (A-20) and the goat-polyclonal antibody Ob-R anti-leptin receptor against the common part of the short and long isoform (M-18; both 1:40 dilution, overnight at $4{ }^{\circ} \mathrm{C}$; Santa Cruz Biotechnology, Santa Cruz, Calif). The primary antibodies were diluted in PBS plus 3\% BSA plus $2 \%$ normal serum. Nonimmune $\operatorname{IgG}$ at the same titer $(0.25 \mu \mathrm{g} / \mathrm{mL})$ as the primary antibodies was used as a negative control. Incubation with appropriate tetramethylrhodamine isothiocyanate- and fluorescein isothiocyanate-conjugated secondary antibodies (both from Jackson Immunoresearch, Immunotech, France) was performed in the dark for 1 hour at room temperature. The antifading agent Slowfade (Molecular Probes, Invitrogen, Carlsbad, Calif) was added, and slides were analyzed by using a confocal laser scanning microscope (SP5 Confocal; Leica, Wetzlar, Germany) equipped with Ar and $\mathrm{HeNe}$ lasers at a final magnification of $\times 630$.

\section{Flow cytometric analysis for leptin receptor}

$16 \mathrm{HBE}$ cells, NHBE cells, and BECs were analyzed for leptin receptor expression by using FACS analysis. All the cells were incubated in the antibody Ob-R for 1 hour at $4^{\circ} \mathrm{C}$. Nonimmune IgG at the same titer $(1 \mu \mathrm{g} / \mathrm{mL})$ as the primary antibody was used as a negative control. Cells were then washed in cold PBS and incubated with fluorescein isothiocyanate-conjugated polyclonal rabbit anti-goat immunoglobulin (DAKO, Glostrup, Denmark) in the dark for 30 minutes at $4^{\circ} \mathrm{C}$. Fluorescence-positive cells were quantified by using a FACSCalibur (Becton Dickinson, Mountain View, Calif) flow cytometer. Percentages of positive cells were determined from forward and sideways scatter patterns. Nonspecific binding and background fluorescence were quantified by analyzing the negative control.

\section{HBE cell treatment}

$16 \mathrm{HBE}$ cells were cultured in the presence or absence of recombinant human TGF- $\beta 1(2 \mathrm{ng} / \mathrm{mL})$ and fluticasone propionate (FP; $10^{-8} \mathrm{M}$; Glaxo SmithKline, Greenford, United Kingdom) for evaluating leptin receptor expression at 24 hours $(n=6)$. Furthermore, $16 \mathrm{HBE}$ cells were cultured in the presence or absence of recombinant human leptin $(0.5 \mu \mathrm{mol} / \mathrm{L})$ and recombinant human TNF- $\alpha$ (30 ng/mL) for TGF- $\beta 1$ release. Experiments were performed from 3 to 6 times at 24 and 48 hours. Anti-TGF- $\beta 1 \mathrm{mAb}$ was used to neutralize the TGF- $\beta 1$ activity, and the pharmacologic inhibitors SB203580 (inhibitor of p38 mitogen-activated protein kinase) and LY294002 (inhibitor of phosphatidylinositol-3-OH kinase; both at $50 \mu \mathrm{mol} / \mathrm{L}$; Sigma, St Louis, Mo) were used to neutralize the leptin activity. ${ }^{2,3}$ The cells were cultured with or without leptin $(0.5 \mu \mathrm{mol} / \mathrm{L})$ for evaluating cell proliferation. All cytokines and antibodies are from R\&D Systems (Minneapolis, Minn).

\section{TGF- $\beta 1$ release by $16 \mathrm{HBE}$ cells}

Supernatants were recovered, centrifuged, and stored at $-80^{\circ} \mathrm{C}$ until assayed. TGF- $\beta 1$ concentrations were measured with a commercially available ELISA Kit (RD; Amersham-Pharmacia Biotech, Little Chalfont, Bucks, United Kingdom). The sensitivity of the assay was $4.0 \mathrm{pg} / \mathrm{mL}$.

\section{Clonogenic assay in 16HBE cells}

The colony growth of $16 \mathrm{HBE}$ cells exposed to leptin for 24 hours was assessed. Detailed methods are described in the Methods section of this article's online repository.

\section{Ex vivo study}

The patients were consecutively recruited and enrolled over a 6-month period. Four groups of subjects were enrolled in this study: healthy control volunteers $(\mathrm{C} ; \mathrm{n}=15)$; subjects with mild uncontrolled untreated asthma (UA $\mathrm{n}=8$ ); subjects with mild asthma controlled with inhaled corticosteroids (ICS; $\mathrm{n}=8$ ), and subjects with severe uncontrolled asthma treated with inhaled and oral corticosteroids (SDA; $n=15)$. Asthmatic subjects were selected according to the last Global Initiative for Asthma guidelines. ${ }^{23}$ They were classified as having uncontrolled asthma according to their recent Asthma Control Questionnaire score ${ }^{24}$ and their exacerbation rate during the last year. ${ }^{25}$ The clinical severity of asthma was assessed by using the Global Initiative for Asthma guidelines and based on the anti-inflammatory treatments used to reach control. ${ }^{18}$ All patients and healthy volunteers were nonsmokers. Subjects who had any bronchial or respiratory tract infections during the month preceding the test were excluded from the study.

\section{Bronchoscopy and tissue processing and staining}

Fiberscopic bronchoscopy was performed by the same physician as previously described. ${ }^{26}$ The detailed methods for biopsy treatments are described in the Methods section of this article's Online Repository.

\section{Statistical analysis}

Results are expressed as means \pm SDs. Unpaired $t$ tests for in vitro experiments and Kruskal-Wallis tests for ex vivo evaluations were performed. A non-parametric Mann Whitney test was then applied between two groups as the initial Kruskal Wallis test was significant. Correlations were determined with a Spearman rank correlation test. A $P$ value of less than .05 was considered statistically significant.

\section{RESULTS \\ Bronchial epithelial cells express leptin/leptin receptor}

NHBE cells, BECs, and 16HBE cells constitutively express leptin and leptin receptor by means of immunofluorescence (NHBE cells) and immunocytochemistry (NHBE cells, BECs, and $16 \mathrm{HBE}$ cells). The results are representative of 3 experiments in each cell line (Fig 1).

\section{Flow cytometric analysis for leptin receptor}

16HBE cells, NHBE cells, and BECs express leptin receptor (Fig 2) by means of FACS analysis. Furthermore, on 16HBE 

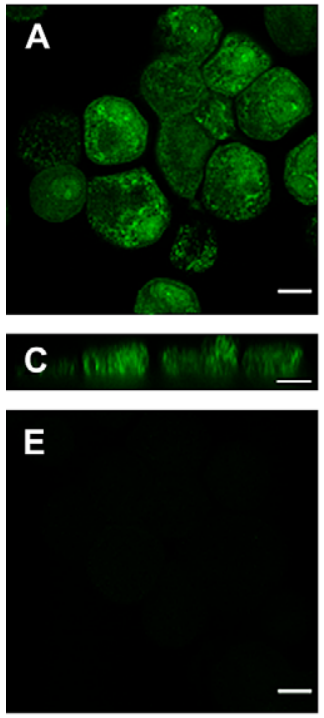

G

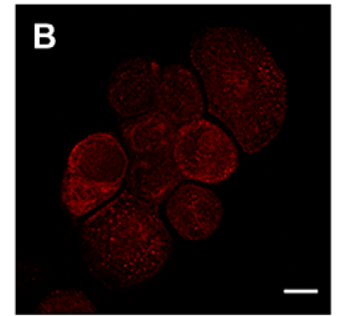

D

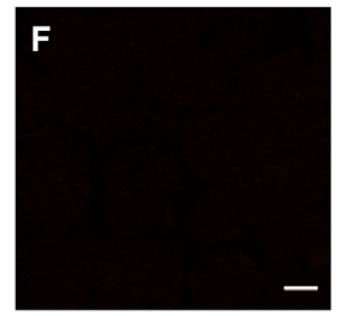

H
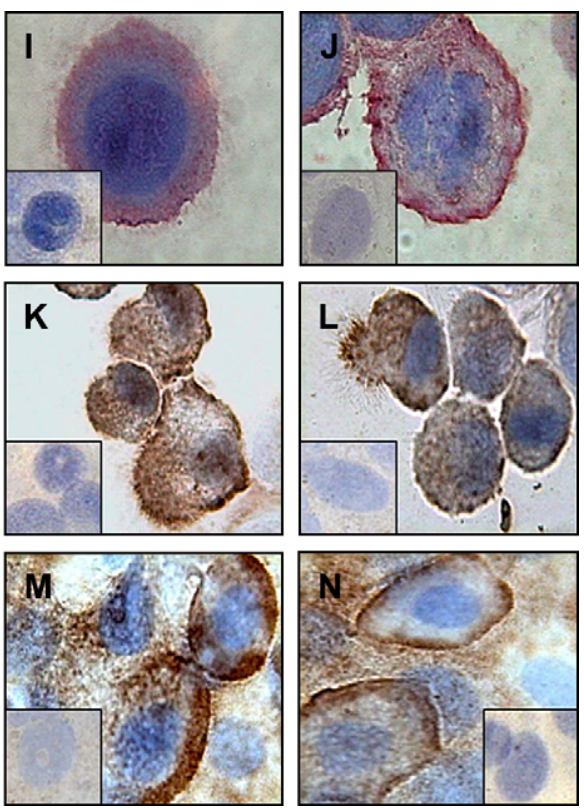

FIG 1. Immunofluorescence from NHBE cells for leptin (A) and leptin receptor (B). Particulars are shown in C and D. The expression of leptin receptor appears more apical than basolateral (magnification $\times 630)$. Bar $=$ $10 \mu \mathrm{m}$. Negative controls are shown in E through H. Immunocytochemistry for leptin (I) and leptin receptor (J) from 16HBE cells (red), NHBE cells ( $\mathbf{K}$ and $\mathbf{L}$ ), and BECs ( $\mathbf{M}$ and $\mathbf{N}$; brown) is also shown (magnification at $\times 1000)$. Insets show negative controls.
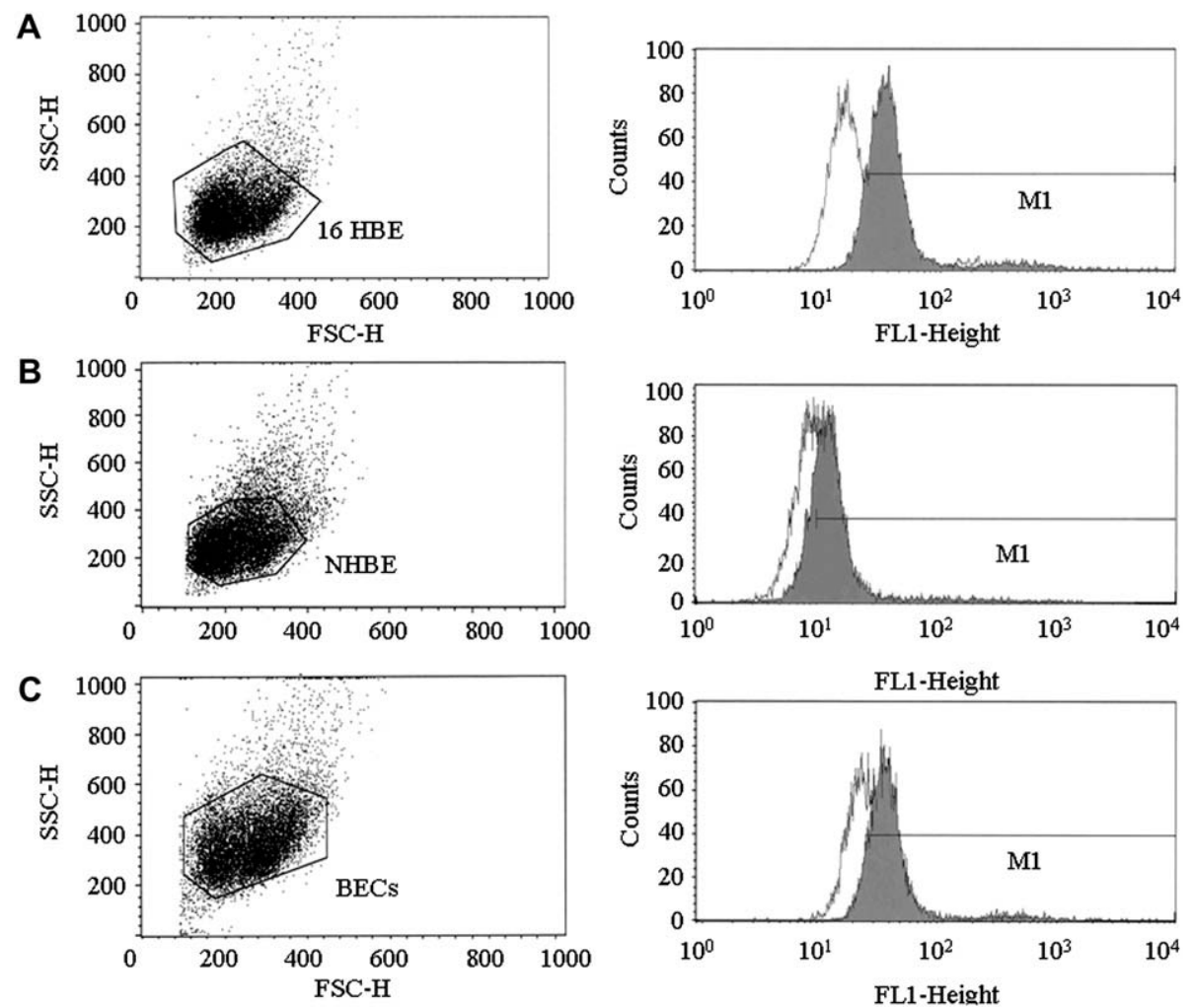

FIG 2. Flow cytometric analysis for leptin receptor expression in $16 \mathrm{HBE}$ cells (A), NHBE cells (B), and BECs (C). Physical parameters (left) and overlay of fluorescence intensity (FL1; right) related to the expression of leptin receptor versus events histogram of cells cultured in medium. White peaks indicate negative controls. $S S C-H$, Side light scatter-height; FSC-H, forward light scatter-height. 


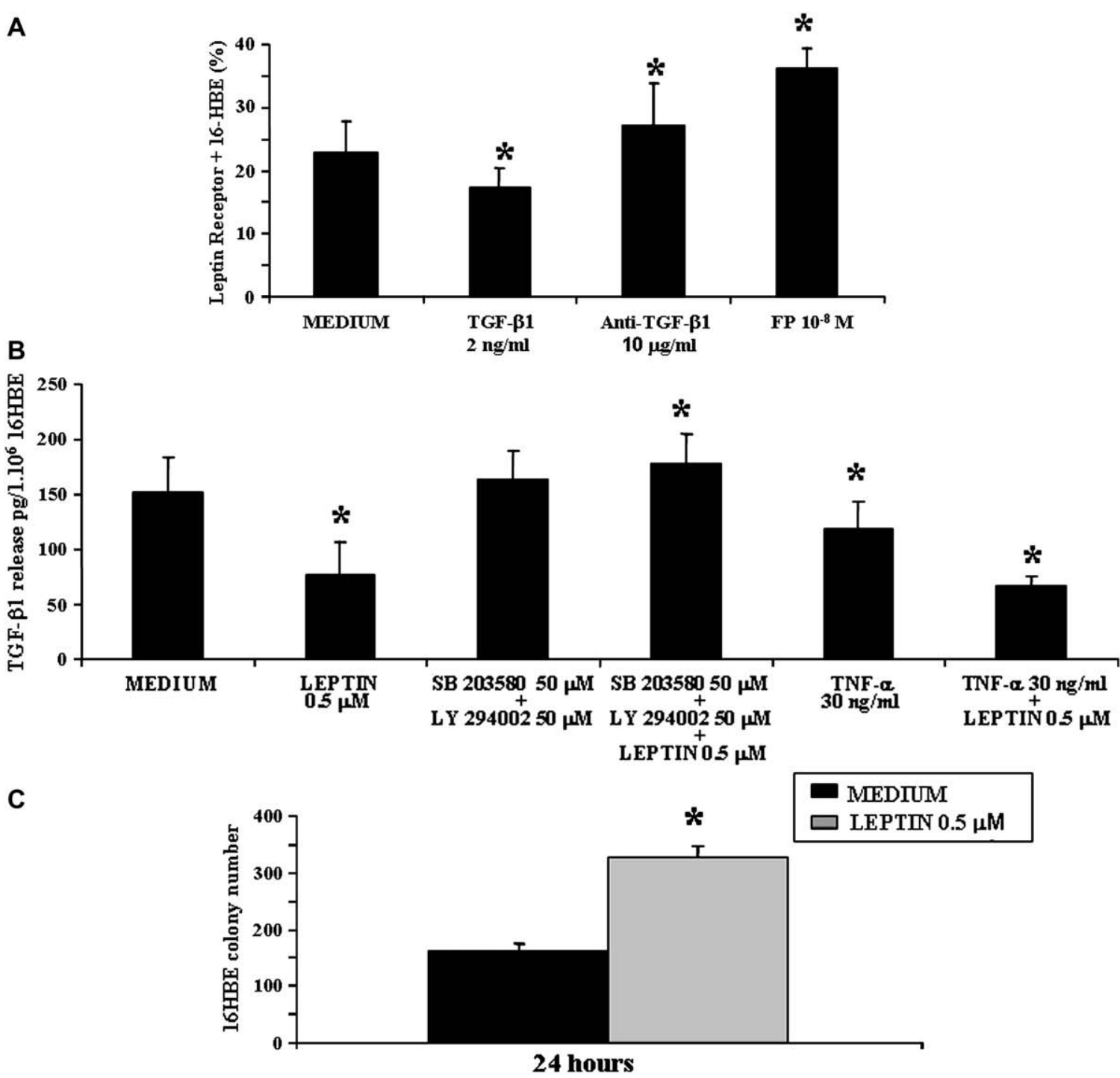

FIG 3. Leptin receptor expression, TGF- $\beta 1$ release, and cell proliferation by $16 \mathrm{HBE}$ cells. A, Leptin receptor expression in $16 \mathrm{HBE}$ cells cultured with medium, TGF- $\beta 1$, FP, and anti-TGF- $\beta 1$. B, Supernatants from $16 \mathrm{HBE}$ cells stimulated with leptin, leptin pharmacologic inhibitors, and TNF- $\alpha$ were assessed for TGF- $\beta 1$ release (ELISA). C, 16HBE colony numbers on leptin incubation. ${ }^{*} P<.05$, unpaired $t$ test.

cells, TGF- $\beta 1$ significantly decreased $(P<.01)$ whereas FP significantly increased $(P<.0005)$ the constitutive leptin receptor expression (Fig 3, $A$ ). The anti-TGF- $\beta 1$ neutralizing mAb completely abrogated the TGF- $\beta 1$ activity $(P<.007$; Fig 3, A).

\section{Leptin decreases TGF- $\beta 1$ release and increases cell proliferation}

On $16 \mathrm{HBE}$ cells, leptin and TNF- $\alpha$ were able to significantly decrease the spontaneous release of TGF- $\beta 1$ both alone $(P<.01$ and $P<.02$, respectively) and combined $(P<.001)$ at both 24 (Fig 3, B) and 48 (data not shown) hours. The pharmacologic inhibitors SB203580 and LY294002 completely abrogated the leptin activity $(P<.03$; Fig $3, B)$. Leptin was able to significantly increase $(P<.001)$ the colony number $($ Fig $3, C)$.

\section{Subjects}

The demographic characteristics and pulmonary functions of the 4 studied groups are reported in Table I.

\section{Leptin/leptin receptor and TGF- $\beta$ expression in bronchial epithelium}

In the bronchial epithelium the expression of leptin (Table II and Fig 4) and its receptor (Table II and Fig 5) was assessed. The expression of both leptin and its receptor was significantly lower in UAs $(P<.001$ and $P<.01)$ and SDAs $(P<.001$ and $P<.001)$ than in $\mathrm{C}$, whereas it was significantly higher in ICS than UA $(P<.03$ and $P<.01)$ and SDA $(P<.01$ and $P<.01)$. Differently, the expression of TGF- $\beta$ was significantly higher in UAs than in the other 3 groups $(P<.01, P<.05$, and $P<.03$, respectively; Table II and Fig 6). 
TABLE I. Demographic characteristics of the subjects

\begin{tabular}{|c|c|c|c|c|}
\hline & C & UA & ICS & SDA \\
\hline Age $(y)$ & $29.5(25-34)$ & $21(20-52)$ & $46(30-51)$ & $53(44-61)$ \\
\hline Sex (M/F ratio) & $62 \%$ & $63 \%$ & $46 \%$ & $63 \%$ \\
\hline $\mathrm{FEV}_{1}(\%$ predicted $)$ & $108.5(103-113.5)$ & $60(53.7-66)$ & $100(97-111.5)$ & $50(40-75.5)$ \\
\hline $\mathrm{ACQ}^{*}$ & NA & $1.5>/<2$ & $<1$ & $>2$ \\
\hline $\begin{array}{l}\text { Exacerbations in last } \\
\text { year } \dagger\end{array}$ & NA & 1 & 0 & $1 / 2$ \\
\hline Allergy (\%) & 0 & 81.8 & 77.7 & 63.6 \\
\hline
\end{tabular}

Data are presented as medians and 25th-75th percentiles.

$N A$, Not applicable.

*Asthma Control Questionnaire Juniper scores.

$\dagger$ Number of exacerbations.

TABLE II. Epithelial markers and RBM thickness

\begin{tabular}{|c|c|c|c|c|c|c|c|c|c|c|}
\hline & $C(n=15)$ & UA $(n=8)$ & ICS $(n=8)$ & $\operatorname{SDA}(n=15)$ & $\begin{array}{c}P \text { value, } \\
\text { C vs } \\
\text { UA }\end{array}$ & $\begin{array}{c}P \text { value, } \\
\text { C vs } \\
\text { ICS }\end{array}$ & $\begin{array}{c}P \text { value, } \\
\text { C vs } \\
\text { SDA }\end{array}$ & $\begin{array}{c}P \text { value, } \\
\text { ICS vs } \\
\text { UA }\end{array}$ & $\begin{array}{l}P \text { value, } \\
\text { ICS vs } \\
\text { SDA }\end{array}$ & $\begin{array}{c}P \text { value, } \\
\text { UA vs } \\
\text { SDA }\end{array}$ \\
\hline $\begin{array}{l}\text { Leptin } \\
\qquad\left(+ \text { cells } / \mathrm{mm}^{2}\right)\end{array}$ & $\begin{array}{l}5,300 \\
\quad(4,031-7,514)\end{array}$ & $\begin{array}{l}2,750 \\
\quad(1,545-3,000)\end{array}$ & $\begin{array}{l}5,722 \\
\quad(3,547-6,761)\end{array}$ & $\begin{array}{l}2,372 \\
\quad(867-3,714)\end{array}$ & $<.001$ & NS & $<.001$ & $<.03$ & $<.01$ & NS \\
\hline $\begin{array}{l}\text { Leptin receptor } \\
\qquad\left(+ \text { cells } / \mathrm{mm}^{2}\right)\end{array}$ & $\begin{array}{l}5,532 \\
\quad(4,209-15,542)\end{array}$ & $\begin{array}{l}3,614 \\
\quad(3,169-3,967)\end{array}$ & $\begin{array}{l}8,098 \\
\quad(5,949-9,996)\end{array}$ & $\begin{array}{l}3,236 \\
\quad(2,509-3,956)\end{array}$ & $<.01$ & NS & $<.001$ & $<.01$ & $<.01$ & NS \\
\hline $\begin{array}{l}\text { TGF- } \beta 1 \\
\quad\left(+ \text { cells } / \mathrm{mm}^{2}\right)\end{array}$ & $\begin{array}{l}2,467 \\
\quad(2,025-2,800)\end{array}$ & $\begin{array}{l}4,265 \\
\quad(3,778-5,760)\end{array}$ & $\begin{array}{l}2,065 \\
\quad(1,094-4,230)\end{array}$ & $\begin{array}{l}2,333 \\
\quad(1,281-3,353)\end{array}$ & $<.01$ & NS & NS & $<.05$ & NS & $<.03$ \\
\hline
\end{tabular}

Data are presented as medians and 25th-75th percentiles. Significance between 2 studied groups was assessed by using the nonparametric Mann-Whitney test.

\section{Assessment of RBM thickness}

RBM thickness was significantly higher in UA, ICS, and SDA than in C (Table II and see Fig E1 in this article's Online Repository at www.jacionline.org).

\section{Correlation analyses}

A positive correlation $(\rho=0.64, P<.001)$ was found between leptin and leptin receptor expression, whereas leptin $(\rho=-0.55$, $P<.001)$ and leptin receptor $(\rho=-0.53, P<.001)$ expressions were inversely correlated with RBM thickness (see Fig E2 in this article's Online Repository at www.jacionline.org). TGF- $\beta$ expression was inversely correlated with leptin $(\rho=-0.48$, $P<.02)$ and leptin receptor expression $(\rho=-0.6, P<.01)$ and positively correlated with RBM thickness $(\rho=0.55, P<$ .01 ) only when SDAs were excluded (see Fig E3 in this article's Online Repository at www.jacionline.org).

\section{DISCUSSION}

In the present study we showed that the leptin/leptin receptor pathway is involved in the structural changes seen in asthma through the commitment of the bronchial epithelium. Here we investigated the contribution of the leptin/leptin receptor pathway in regulating TGF- $\beta$ expression on epithelial behavior in vitro and airway remodeling in subjects with asthma of various severities.
First, human bronchial epithelial cells constitutively express leptin and leptin receptor in vitro. Second, the constitutive expression of leptin receptor is decreased by TGF- $\beta 1$ and increased by FP in vitro. Third, leptin decreases the spontaneous release of TGF$\beta 1$ and increases bronchial epithelial cell proliferation through its receptor. Fourth, leptin/leptin receptor pathway expression in bronchial epithelium is lower in patients with mild uncontrolled untreated and severe uncontrolled treated asthma when compared with the other 2 categories. Fifth, abnormalities linked to airway remodeling were observed in endobronchial biopsy specimens from asthmatic subjects. Finally, the lack of leptin/leptin receptor expression is associated with markers of airway remodeling in patients with severe asthma.

Leptin might play a key role in asthma remodeling and in physiologic bronchial epithelial proliferation. Earlier studies suggested that leptin is involved in the pathophysiology of inflammatory processes and immune responses and regulates the epithelial homeostasis in different compartments. ${ }^{27,28}$ Asthma is characterized by airflow obstruction, airway inflammation, and structural changes in the airways. ${ }^{29,30}$ Although information concerning the genesis of inflammation is abundant, the precise factors responsible for airway remodeling and for the variable efficacy of corticosteroid treatment in patients with severe asthma are unknown.

In the bronchi we already reported a reduced expression of leptin/leptin receptor in epithelial cells of smokers and patients 
A
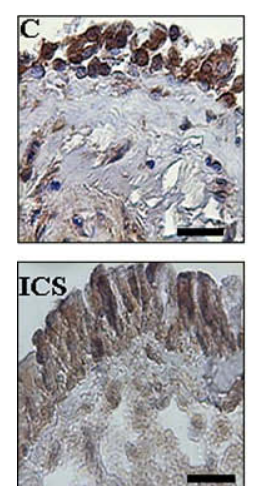
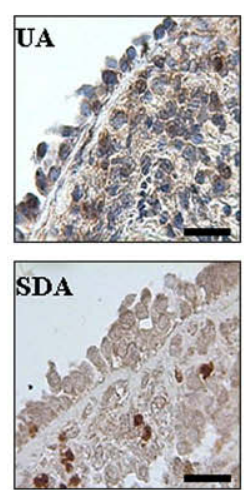

B

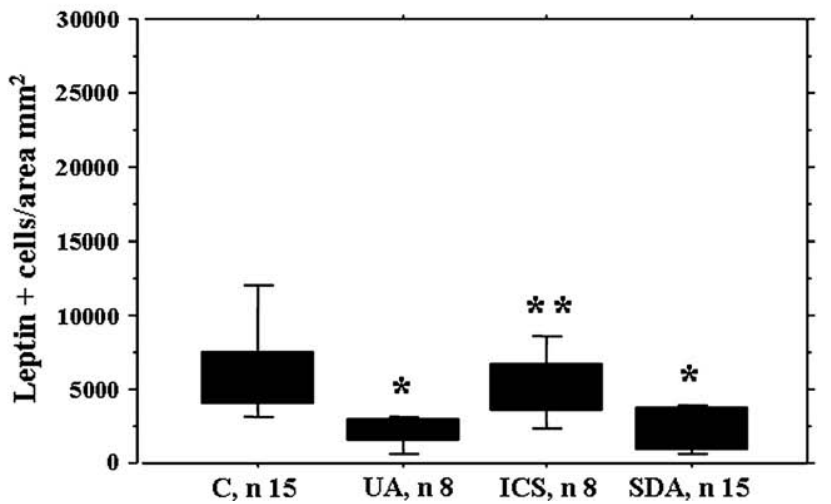

FIG 4. A, Immunohistochemistry for leptin on epithelium from bronchial biopsy specimens (brown). Healthy volunteers (C) and subjects with mild uncontrolled (UA), mild controlled (ICS), and severe (SDA) asthma are shown (magnification at $\times 400$ ). Scale bar $=40 \mu \mathrm{m}$. B, Leptin expression is significantly lower* in the UA $(P<.001)$ and SDA $(P<.001)$ groups versus the $C$ group and significantly higher** in the ICS group vs the UA $(P<.03)$ and SDA $(P<.01)$ groups.

A
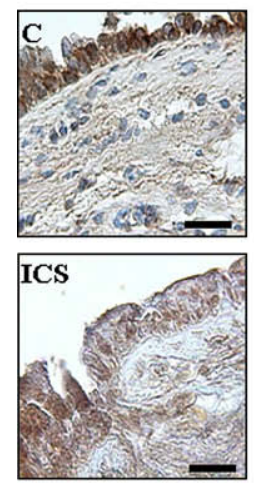
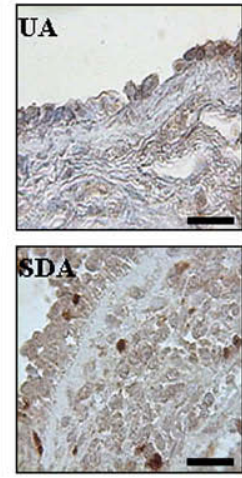

B

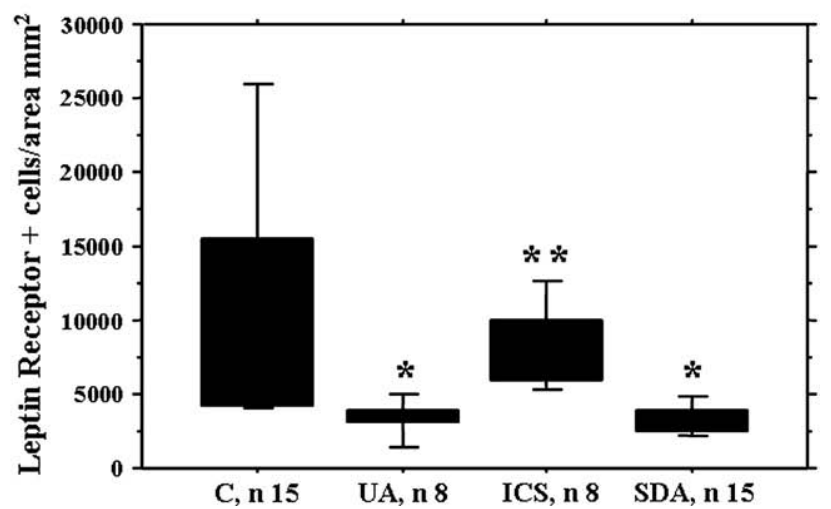

FIG 5. A, Immunohistochemistry for leptin receptor on epithelium from bronchial biopsy specimens (brown) of healthy volunteers (C) and subjects with mild uncontrolled (UA), mild controlled (ICS), and severe $(S D A)$ asthma (magnification at $\times 400)$. Scale bar $=40 \mu \mathrm{m}$. B, Leptin receptor expression is significantly lower* in the UA $(P<.01)$ and SDA $(P<.001)$ groups versus the $\mathrm{C}$ group and significantly higher** in the ICS group versus the UA $(P<.01)$ and $\operatorname{SDA}(P<.01)$ groups.

with chronic obstructive pulmonary disease, ${ }^{4}$ suggesting a role of the leptin/leptin receptor pathway in the homeostasis of lung tissue. Airway remodeling is a complex process that involves all the airway tissue components from the epithelium to the adventitia. Therefore the question of whether the adipokine leptin is involved in the functional response to airway remodeling in patients with severe asthma seems to be of interest. The expression of the leptin/leptin receptor pathway was first demonstrated in in vitro differentiated NHBE cells, in BECs, and in the 16HBE cell line. TGF- $\beta 1$ significantly reduced and FP significantly increased the expression of leptin receptor. On the other hand, leptin was able to significantly reduce TGF- $\beta 1$ release and to significantly increase cell proliferation. All these findings demonstrate that physiologically in the bronchial epithelium, the leptin/leptin receptor pathway might negatively regulate the overproduction of TGF- $\beta 1$, which, in turn, might exert a negative feedback on leptin receptor expression.

These findings prompted us to investigate the leptin/leptin receptor and TGF- $\beta$ expressions in fully differentiated and polarized epithelium of bronchial biopsy specimens from healthy volunteers and from subjects with asthma of various severities. The RBM thickness was also assessed to explore the potential relationships between airway remodeling and leptin pathway expressions. Increased subepithelial thickness has been associated with severe asthma. ${ }^{31}$

Profibrogenic cytokines, such as TGF- $\beta$, promote transdifferentiation of epithelial cells into fibroblasts through a process called epithelial-mesenchymal transition. ${ }^{32}$ TGF- $\beta$ is increased within the airways in patients with asthma ${ }^{16,33,34}$ and contributes to the abnormal activation of the epithelial-mesenchymal trophic unit, ${ }^{35}$ a crucial event in airway remodeling. The overproduction of TGF- $\beta$ increases the number and activity of subepithelial myofibroblasts and increases collagen deposition, leading to the thickening of the subepithelial layer beneath the RBM. ${ }^{36}$ Leptin is also important in lung development in the differentiation of lipofibroblasts to normal fibroblasts. ${ }^{37}$ In this study we found that the epithelial expression of both leptin and its receptor is significantly lower in patients with mild uncontrolled untreated and severe treated asthma than in patients with mild controlled treated asthma and healthy volunteers, further supporting a dysregulation 
A
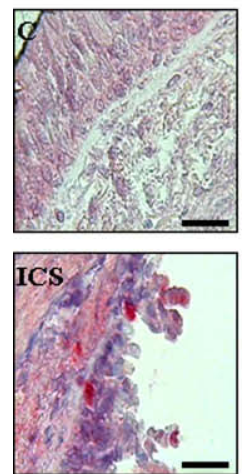
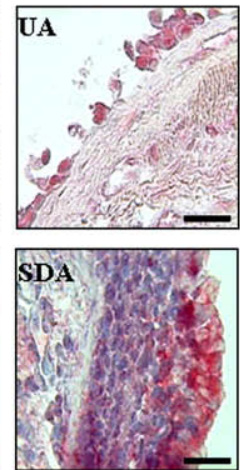

B

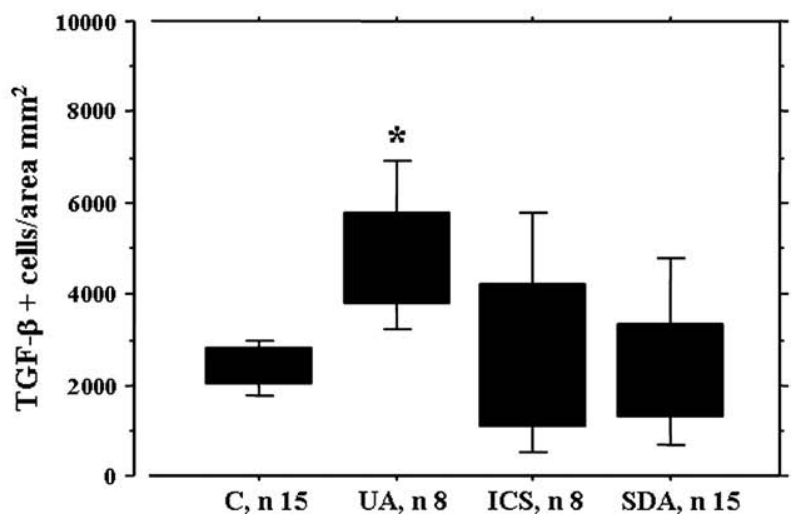

FIG 6. A, Immunohistochemistry for TGF- $\beta$ on epithelium from bronchial biopsy specimens (red) of healthy volunteers $(C)$ and subjects with mild uncontrolled (UA), mild controlled (ICS), and severe (SDA) asthma (magnification at $\times 400$ ). Scale bar $=40 \mu \mathrm{m}$. B, TGF- $\beta$ expression is significantly higher* in the UA group versus the $\mathrm{C}(P<.01)$, ICS $(P<.05)$, and SDA $(P<.03)$ groups.

of the leptin/leptin receptor pathway linked to asthma control and bronchial inflammation. The expression of leptin positively correlated with leptin receptor expression, whereas leptin and leptin receptor expression are inversely correlated with subepithelial thickness and TGF- $\beta$ expression. Furthermore, TGF- $\beta$ expression is higher in patients with mild uncontrolled untreated asthma and is positively associated with RBM thickness.

These results confirm previous findings showing that TGF- $\beta$ expression is correlated with subepithelial layer thickness, ${ }^{15,38}$ fibroblast numbers, and disease severity, extending these observations also to patients with severe asthma in whom changes in the subepithelial layer are paramount, although their significance remains speculative. ${ }^{34}$ Interestingly, in subjects with mild controlled treated asthma the expression of the leptin/leptin receptor pathway, the expression of the fibrogenic cytokine TGF- $\beta$, and the subepithelial thickness are mostly comparable with what it is observed in the normal situation. These findings suggest that the treatment of patients with inhaled corticosteroids and longacting $\beta_{2}$-agonists might restore some of the structural changes in certain phenotype of asthma. Differently, in subjects with severe uncontrolled treated asthma, the persistence of increased RBM thickness and of reduced leptin/leptin receptor pathway expression despite the use of high doses of corticosteroids suggests that the lack of this therapy in controlling the disease in these patients might also be related to the lack of effects in affecting leptin/leptin receptor pathway expression and consequently RBM thickness. Furthermore, in patients with severe uncontrolled treated asthma, we did not find any association between TGF- $\beta$ and the leptin/leptin receptor pathway or between TGF- $\beta$ and subepithelial layer thickness. Taken together, these findings strongly support the concept that leptin/leptin receptor pathway might control the subepithelial layer thickness without the intervention of TGF- $\beta$ production in severe asthma. Longitudinal studies might help to better understand the dynamic process involved in the epithelial changes. The persistent neutrophilic inflammation associated with a decreased response to corticosteroids in patients with severe asthma might contribute to the persistence of an altered leptin/leptin receptor pathway.

This study contributes to the description of severe asthma as a condition in which aberrant communication between an injured airway epithelium and the underlying mesenchyma contributes to disease chronicity and refractoriness to corticosteroids. ${ }^{18}$ In this study we found that the leptin/leptin receptor pathway and TGF- $\beta$ have the opposite trend of expression in bronchial epithelium according to the control and severity of asthma.

The present study provides evidences of a novel link between leptin receptor activity and the production of TGF- $\beta$ in human bronchial epithelial cells in vitro and in bronchial biopsy specimens from healthy control subjects and asthmatic patients. The data show that an active leptin signaling pathway is present in lung epithelial tissue and that its activity is downregulated in subjects with severe asthma and correlates with markers of airway remodeling. Although recombinant leptin can suppress spontaneous release of TGF- $\beta 1$ in vitro, a feedback mechanism appears to be in place because exposure of cells to recombinant TGF- $\beta 1$ causes leptin receptor expression to fall. As a consequence, this pathway might represent a useful marker to better understand, follow, and treat patients with severe asthma.

We thank Dr Leon Espinosa, URMITE CNRS IRD 6236, Marseille, France, for excellent confocal microscope analysis and Brigitte Mainprice and Martine Farce (both of MED BIO MED, Clinique des Maladies Respiratoires, CHU Montpellier, France) for excellent technical assistance.

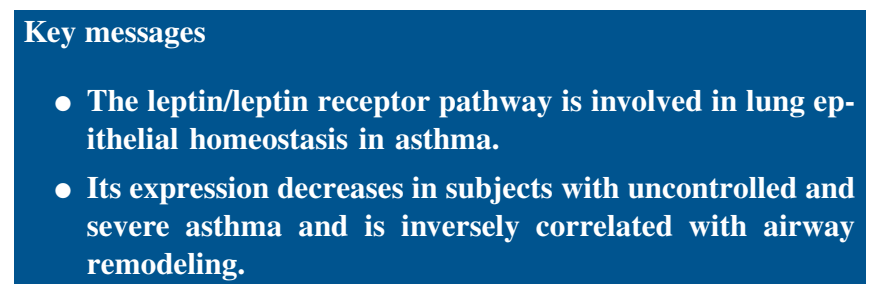

\section{REFERENCES}

1. Matarese G, Mantzoros C, La Cava A. Leptin and adipocytokines: bridging the gap between immunity and atherosclerosis. Curr Pharm Des 2007;13:3676-80.

2. Conus S, Bruno A, Simon HU. Leptin is an eosinophil survival factor. J Allergy Clin Immunol 2005;116:1228-34.

3. Bruno A, Conus S, Schimd I, Simon HU. Apoptotic pathways are inhibited by leptin receptor activation in neutrophils. J Immunol 2005;174:8090-6.

4. Bruno A, Chanez P, Chiappara G, Siena L, Giammanco S, Gjomarkaj M, et al. Does leptin play a cytokine-like role within the airways of COPD patients? Eur Respir J 2005;26:398-405. 
5. Goren I, Kämpfer H, Podda M, Pfeilschifter J, Frank S. Leptin and wound inflammation in diabetic ob/ob mice: differential regulation of neutrophil and macrophage influx and a potential role for the scab as a sink for inflammatory cells and mediators. Diabetes 2003;52:2821-32.

6. Bergen HT, Cherlet TC, Manuel P, Scott JE. Identification of leptin receptors in lung and isolated fetal type II cells. Am J Respir Cell Mol Biol 2002;27:71-7.

7. Wolk R, Deb A, Caplice NM, Somers VK. Leptin receptor and functional effects of leptin in human endothelial progenitor cells. Atherosclerosis 2005;183:131-9.

8. Shore SA, Schwartzman IM, Mellema MS, Flynt L, Imrich A, Johnston RA. Effect of leptin on allergic airway responses in mice. J Allergy Clin Immunol 2005;115: 103-9.

9. Burgel PR, Nadel JA. Epidermal growth factor receptor-mediated innate immune responses and their roles in airway diseases. Eur Respir J 2008;32:1068-81.

10. James AL, Wenzel S. Clinical relevance of airway remodelling in airway diseases. Eur Respir J 2007;30:134-55.

11. Jeffery PK. Remodelling in asthma and chronic obstructive lung disease. Am J Respir Crit Care Med 2001;164(suppl):S28-38.

12. Holgate ST, Peters-Golden M, Panettieri RA, Henderson WR Jr. Roles of cysteinyl leukotrienes in airway inflammation, smooth muscle function, and remodelling. J Allergy Clin Immunol 2003;111(suppl):S18-34.

13. Roberts CR. Is asthma a fibrotic disease? Chest 1995;107(suppl):111s-7s.

14. Vignola AM, Kips J, Bousquet J. Tissue remodelling as a feature of persistent asthma. J Allergy Clin Immunol 2000;105:1041-53.

15. Vignola AM, Chanez P, Chiappara G, Merendino A, Pace E, Rizzo A, et al. Transforming growth factor- $\beta$ expression in mucosal biopsies in asthma and chronic bronchitis. Am J Respir Crit Care Med 1997;156:591-9.

16. Profita M, Gagliardo R, Di Giorgi R, Bruno A, Riccobono L, Bonanno A, et al. In vitro effects of flunisolide on MMP-9, TIMP-1, fibronectin, TGF-beta1 release and apoptosis in sputum cells freshly isolated from mild to moderate asthmatics. Allergy 2004;59:927-32.

17. Chanez P. Severe asthma is an epithelial disease. Eur Respir J 2005;25:945-6.

18. Chanez P, Wenzel SE, Anderson GP, Anto JM, Bel EH, Boulet LP, et al. Severe asthma in adults: what are the important questions? J Allergy Clin Immunol 2007; 119:1337-48.

19. Chen XL, Hausman DB, Dean RG, Hausman GJ. Hormonal regulation of leptin mRNA expression and preadipocyte recruitment and differentiation in porcine primary cultures of S-V cells. Obes Res 1998;6:164-72.

20. Lee MJ, Wang Y, Ricci MR, Sullivan S, Russell CD, Fried SK. Acute and chronic regulation of leptin synthesis, storage, and secretion by insulin and dexamethasone in human adipose tissue. Am J Physiol Endocrinol Metab 2007;292:E858-64.

21. Wyrwoll CS, Mark PJ, Waddell BJ. Directional secretion and transport of leptin and expression of leptin receptor isoforms in human placental BeWo cells. Mol Cell Endocrinol 2005;241:73-9.

22. Cozens AL, Yezzi MJ, Kunzelmann K, Ohrui T, Chin L, Eng K, et al. CFTR expression and chloride secretion in polarized immortal human bronchial epithelial cells. Am J Respir Cell Mol Biol 1994;10:38-47.
23. Global Initiative for Asthma (GINA). Available at: www.ginasthma.org. Accessed 2008 .

24. Juniper EF, O'Byrne PM, Guyatt GH, Ferrie PJ, King DR. Development and validation of a questionnaire to measure asthma control. Eur Respir J 1999;14: 902-7.

25. Pauwels RA, Löfdahl CG, Postma DS, Tattersfield AE, O'Byrne P, Barnes PJ, et al. Effect of inhaled formoterol and budesonide on exacerbations of asthma. Formoterol and Corticosteroids Establishing Therapy (FACET) International Study Group. N Engl J Med 1997;337:1405-11.

26. Chanez P, Vignola AM, Vic P, Guddo F, Bonsignore G, Godard P, et al. Comparison between nasal and bronchial inflammation in asthmatic and control subjects. Am J Respir Crit Care Med 1999;159:588-95.

27. Hansen GH, Niels-Christiansen LL, Danielsen EM. Leptin and the obesity receptor (OB-R) in the small intestine and colon: a colocalization study. J Histochem Cytochem 2008;56:677-85.

28. Feuermann Y, Mabjeesh SJ, Niv-Spector L, Levin D, Shamay A. Prolactin affects leptin action in the bovine mammary gland via the mammary fat pad. J Endocrinol 2006; 191:407-13.

29. Fixman ED, Stewart A, Martin JG. Basic mechanisms of development of airway structural changes in asthma. Eur Respir J 2007;29:379-89.

30. Holgate ST. The airway epithelium is central to the pathogenesis of asthma. Allergol Int 2008;57:1-10.

31. Bourdin A, Neveu D, Vachier I, Paganin F, Godard P, Chanez P. Specificity of basement membrane thickening in severe asthma. J Allergy Clin Immunol 2007;119 1367-74.

32. Willis BC, Liebler JM, Luby-Phelps K, Nicholson AG, Crandall ED, du Bois RM, et al. Induction of epithelial-mesenchymal transition in alveolar epithelial cells by transforming growth factor-beta 1: potential role in idiopathic pulmonary fibrosis. Am J Pathol 2005;166:1321-32.

33. Balzar S, Chu HW, Silkoff P, Cundall M, Trudeau JB, Strand M, et al. Increased TGF-beta2 in severe asthma with eosinophilia. J Allergy Clin Immunol 2005; 115:110-7.

34. Wenzel SE, Balzar S, Cundall M, Chu HW. Subepithelial basement membrane immunoreactivity for matrix metalloproteinase 9: association with asthma severity, neutrophilic inflammation, and wound repair. J Allergy Clin Immunol 2003;111: 1345-52.

35. Holgate ST. Epithelial dysfunction in asthma. J Allergy Clin Immunol 2007;120: 1233-44.

36. Knight DA, Holgate ST. The airway epithelium: structural and functional properties in health and disease. Respirology 2003;8:432-46.

37. Torday JS, Sun H, Wang L, Torres E, Sunday ME, Rubin LP. Leptin mediates the parathyroid hormone-related protein paracrine stimulation of fetal lung maturation. Am J Physiol Lung Cell Mol Physiol 2002;282:L405-10.

38. Karjalainen EM, Lindqvist A, Laitinen LA, Kava T, Altraja A, Halme M, et al Airway inflammation and basement membrane tenascin in newly diagnosed atopic and nonatopic asthma. Respir Med 2003;97:1045-51. 


\section{METHODS}

\section{Cell-line cultures}

The human bronchial epithelial SV40 immortalized cell line 16HBE 14 owas derived from the epithelium of second-generation bronchi. The 16HBE cells forming polarized monolayers with intact tight junctions were cultured in modified Eagle medium plus $10 \%$ heat-inactivated (at $56^{\circ} \mathrm{C}$ for 30 minutes) FBS plus gentamicin solution ( $25 \mathrm{mg}$ per $100 \mathrm{~mL}$ ) plus $1 \mathrm{mmol} / \mathrm{L}$ L-glutamine and $25 \mathrm{mmol} / \mathrm{L}$ HEPES (all from Invitrogen-GIBCO, Grand Island, NY).

Primary NHBE cells (Lonza) were cultured in bronchial epithelial growth medium (Lonza) by using both a plastic monolayer system and an air/liquid interface system. ${ }^{\mathrm{E}}$ Cells were plated on uncoated nucleopore membranes (24-mm diameter, 0.4-mm pore; Transwell Clear, Cambridge, Mass) in a 1:1 mixture of bronchial epithelial growth medium and Dulbecco modified Eagle medium (Invitrogen) supplemented with BSA $(1.5 \mathrm{mg} / \mathrm{mL})$ and retinoic acid $(50 \mathrm{nmol} / \mathrm{L})$ and applied at the basal side only to establish an air/liquid interface. Cells were maintained in culture for 21 days to obtain a differentiated cell population with a mucociliary phenotype.

16HBE and NHBE cells were treated with trypsin and then used for further evaluations.

Bronchial brushings obtained from subjects with no macroscopic bronchial abnormalities by using a protected brush (Olympus, Center Valley, Pa) to sample bronchial subsegments were placed in RPMI 1640 (10\% FBS, $100 \mathrm{U} / \mathrm{mL}^{-1}$ and streptomycin $100 \mu \mathrm{g} / \mathrm{mL}$ ) and then vortexed and centrifuged to separate bronchial epithelial cells (BECs). The cell viability of BECs was assessed.

\section{Immunocytochemistry}

Cytospin preparations were made from 16HBE cells, NHBE cells, and BECs, and cells were fixed and permeabilized as previously described. After washing in PBS, slides were incubated with the primary antibodies Ob (1:40 dilution for 1 hour at room temperature) and Ob-R (1:20 dilution overnight at $\left.4^{\circ} \mathrm{C}\right)$. The reaction was revealed by using the LSAB KIT phosphatase method for 16HBE cells and by using LSAB + KIT-HRP (all from DAKO) for NHBE cells and for BECs, according to the manufacturer's instructions. Nonimmune IgG at the same titer $(0.25 \mu \mathrm{g} / \mathrm{mL}$ for $\mathrm{Ob}$ and $1 \mu \mathrm{g} / \mathrm{mL}$ for $\mathrm{Ob}-\mathrm{R})$ as the primary antibodies was used as a negative control. Cytospin preparations were examined under light microscopy at a final magnification of $\times 1000$.

\section{Clonogenic assay in 16HBE cells}

In 35-mm Petri dishes (Falcon, Becton Dickinson, Franklin Lakes, NJ) a lower layer was prepared by using complete modified Eagle medium in $0.5 \%$ agarose. After incubation, cells were harvested and seeded $\left(5 \times 10^{4}\right)$ on the upper layer with $0.3 \%$ agarose prepared with the same medium as the lower layer and finally incubated for 21 days at $37^{\circ} \mathrm{C}$ in an atmosphere containing
$0.5 \% \mathrm{CO}_{2}$. At the end of incubation, colonies were counted under an inverted phase-contrast microscope (Leitz, Wetzlar, Germany). The experiment was conducted in triplicate. Colonies were defined as cell aggregates with at least 40 cells. The true number of colonies was calculated as the number of aggregates on the positive control subtracted from the number of colonies on the experimental plates. The results are expressed as percentages of the control value.

\section{Bronchoscopy and tissue processing and staining}

Four to 6 bronchial biopsy specimens were taken from each subject by using the same forceps on a subsegmental bronchus of the lower left lobe. Endobronchial biopsy specimens were fixed in 10\% formaldehyde ( $\mathrm{pH} 7.2)$ and embedded in paraffin. Four-micrometer tissue sections were attached to polylysine-coated microscope slides and, after dewaxing and rehydration, were stained with hematoxylin or analyzed by means of immunohistochemistry. Tissue sections were immunostained with the antibodies Ob (1:50 dilution for 1 hour at room temperature), Ob-R (1:70 dilution for 1 hour at room temperature), $\mathrm{mAb}$ anti-TGF- $\beta 1$, anti-TGF- $\beta 2$, and anti-TGF- $\beta 3$ (MAB1835 $40 \mu \mathrm{g} / \mathrm{mL}$ dilution for 1 hour at room temperature; R\&D Systems). Control slides were prepared by using an irrelevant antibody of the same isotype and at the same concentration as the specific primary antibodies $(0.20 \mu \mathrm{g} / \mathrm{mL}$ for $\mathrm{Ob}, 0.14 \mu \mathrm{g} / \mathrm{mL}$ for $\mathrm{Ob}-\mathrm{R}$, and $1.2 \mu \mathrm{g} / \mathrm{mL}$ for MAB1835). The immunoreactions were revealed by using the LSAB + KITHRP and APAAP techniques (all from DAKO) for leptin/leptin receptor and TGF- $\beta$ expressions, respectively.

\section{Microscopic analysis and RBM thickness assessment}

Biopsy samples were examined with a Leica light microscope. In the epithelium positive cells for leptin, leptin receptor, and TGF- $\beta$ were evaluated per area over a minimum length of $260 \mu \mathrm{m}$ from the internal side of the epithelium, with a final magnification of $\times 400$. RBM thickness was expressed as the average area/length ratio in the valuable region by using the Wilson method, as previously recommended, ${ }^{\mathrm{E} 2}$ with a final magnification of $\times 1,250$. The images were subsequently analyzed with Quantimet $500 \mathrm{MC}$ software (Leica) for image analysis. All biopsy samples were coded, and sections were analyzed in a blinded fashion by 2 independent investigators.

\section{REFERENCES}

E1. Bonnans C, Fukunaga K, Levy MA, Levy BD. Lipoxin A4 regulates bronchial epithelial cell responses to acid injury. Am J Pathol 2006;168:1064-72.

E2. Wilson JW, Li X. The measurement of reticular basement membrane and submucosal collagen in the asthmatic airway. Clin Exp Allergy 1997;27:363-71. 
A
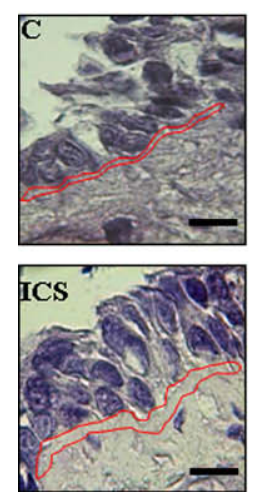
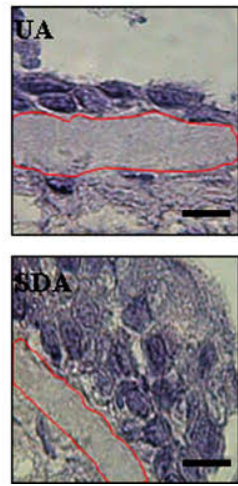

B

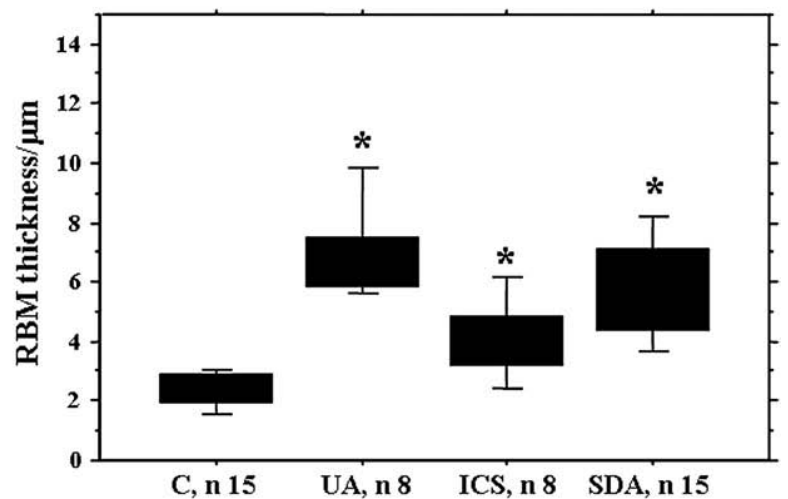

FIG E1. A, Hematoxylin staining for RBM thickness from bronchial biopsy specimens (blue; magnification $\times 400$ ). Scale bar $=40 \mu \mathrm{m}$. B, RBM thickness is significantly higher* in subjects with mild uncontrolled asthma (UA; $\mathrm{n}=8 ; P<.01)$, subjects with mild controlled asthma (ICS; $\mathrm{n}=8 ; P<.04)$, and subjects with severe asthma $(S D A ; \mathrm{n}=15 ; P<0.001)$ versus healthy control volunteers $(\mathbf{C} ; \mathrm{n}=15)$. 

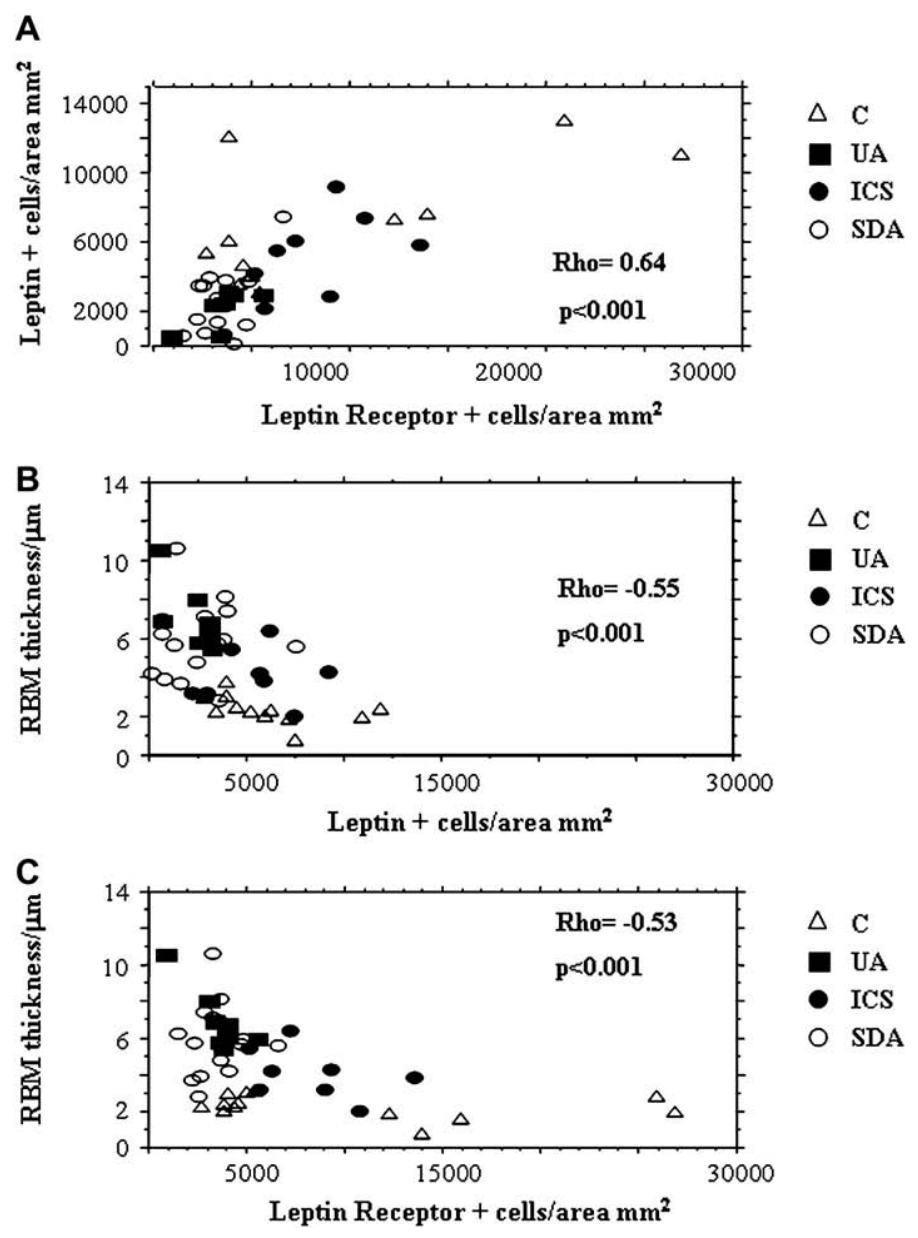

FIG E2. Correlations between leptin/leptin receptor and RBM. In bronchial epithelium leptin and leptin receptor expressions are positively correlated with each other (A). Leptin (B) and leptin receptor (C) expressions are inversely correlated with RBM thickness. Healthy volunteers $(C ; n=15)$ and subjects with mild uncontrolled $(U A ; \mathrm{n}=8)$, mild controlled $(I C S ; \mathrm{n}=8)$, and severe $(S D A ; \mathrm{n}=15)$ asthma are shown. 


\section{A}

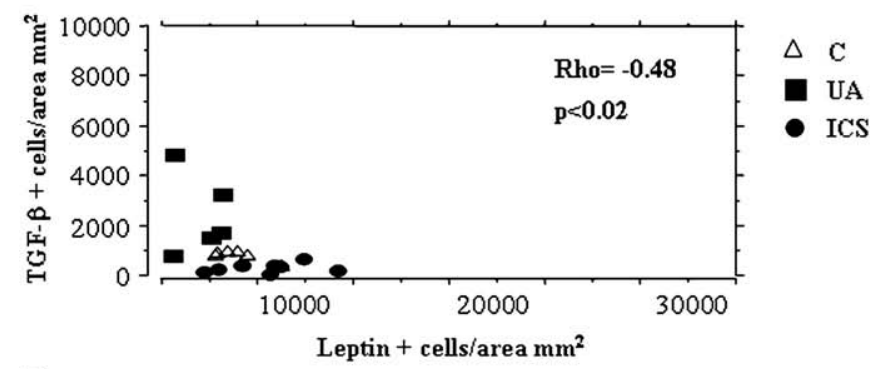

B
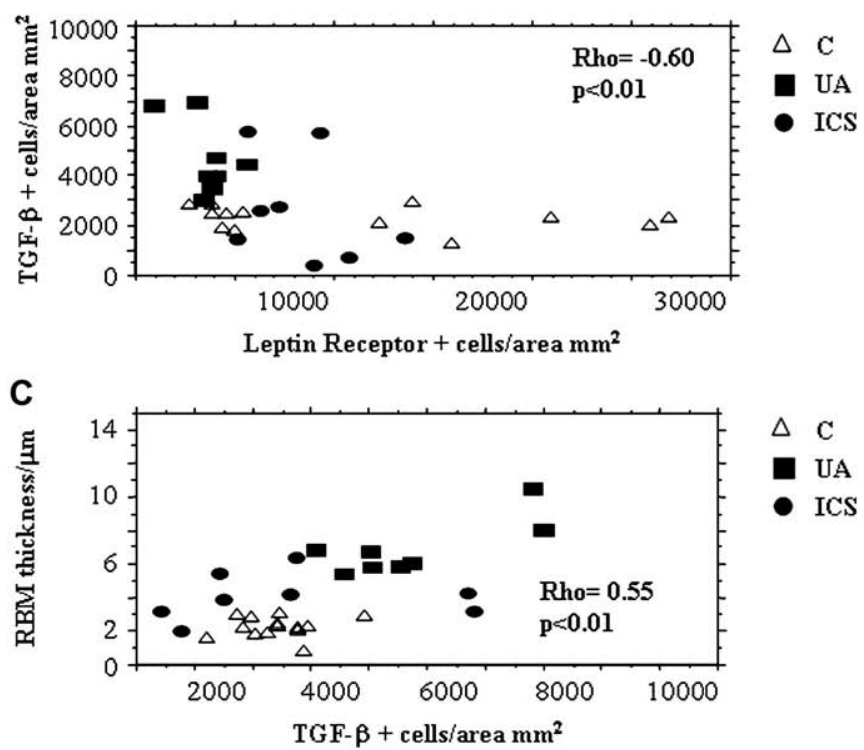

FIG E3. Correlations between leptin/leptin receptor, TGF- $\beta$, and RBM. In bronchial epithelium leptin (A) and leptin receptor (B) expressions are inversely correlated with TGF- $\beta$ expression. TGF- $\beta$ expression is positively correlated with RBM thickness (C). Healthy control volunteers ( $C ; \mathrm{n}=15)$ and subjects with mild uncontrolled $(U A ; \mathrm{n}=8)$ and mild controlled (ICS; $\mathrm{n}=8$ ) asthma are shown. 